\title{
G (2) \\ Understanding the protective roles of Indian joint families for children during the early phase of the COVID-19 pandemic
}

\section{Gyanesh Kumar Tiwari ( $\sim$ gyaneshpsychology@gmail.com )}

Dr Harisingh Gour University, Sagar, 470003, Madhya Pradesh, India https://orcid.org/0000-0002-6880940X

\section{Rakesh Pandey}

Banaras Hindu University, Varanasi, 221005, Uttar Pradesh, India https://orcid.org/0000-0001-8024$300 \mathrm{X}$

\section{Devaki Nandan Sharma}

Dr Harisingh Gour University, Sagar, 470003, Madhya Pradesh, India https://orcid.org/0000-0002-8988349X

\section{Bablu Ray}

Dr Harisingh Gour University, Sagar, 470003, Madhya Pradesh, India https://orcid.org/0000-0002-35726077

\section{Abhigyan Dwivedi}

Dr Harisingh Gour University, Sagar, 470003, Madhya Pradesh, India https://orcid.org/0000-0002-39959599

\section{Ajit Kumar Singh}

Dr Harisingh Gour University, Sagar, 470003, Madhya Pradesh, India https://orcid.org/0000-0002-51268221

\section{Pankaj Singh}

Dr Harisingh Gour University, Sagar, 470003, Madhya Pradesh, India https://orcid.org/0000-0001-93592874

\section{Research Article}

Keywords: children, collective values, COVID-19 pandemic, Indian joint family, perceived outcomes, thematic analysis method

Posted Date: March 2nd, 2022

DOI: https://doi.org/10.21203/rs.3.rs-1399215/v1 
License: (c) (i) This work is licensed under a Creative Commons Attribution 4.0 International License. Read Full License 


\section{Abstract}

The COVID-19 is exerting deleterious impacts on children. We intend to understand the protective roles of Indian joint families for the perceived life outcomes of children (9-12 years) during the early phase of the current pandemic. The qualitative study revealed six themes: perceived distress, the multiplicity of relationships, harmonious relationships, involvement in household activities, facilitating role of the elders, and collective values and practices. The uncertainty and fear enhanced the perceived distress of the family members and concerns for children. The abundant supportive relational resources, involvement in household activities, warmth, optimism and cooperation of the elderly and interdependence and religious practices were the resources described to protect the children from the pandemic's ill-effects. Indian joint families adhere to collectivistic values which may have facilitated more support, cooperation, care, interdependence, discipline, cultural knowledge, and conflict resolution mechanisms. Integrity, emotional stability and care of the elderly may have significant protective forces.

\section{Introduction}

The recent outbreak of the COVID-19 pandemic has led to the development of negative life outcomes for people of all age groups including children (Wang et al., 2020). Among others, children have been a big sufferer of the pandemic due to the school closure, restrictions on their social interactions, play, uncertainty and parental distress (Jiao et al., 2020; Wang et al., 2020). World Health Organization (2021) feared that some children may feel strong isolation, anxiety, boredom and uncertainty as well as may experience fear and grief due to the negative impacts on their families caused by the pandemic. Research suggests that the uncertainties, fear and loss caused by the COVID-19 pandemic have led to the development of severe distress, panic and fierce challenges equal to the existence of children and adults (Jiao et al., 2020; Tiwari et al., 2021; Wang et al., 2020). In its initial observations, United Nations Organization (2020) has feared that children may be the biggest sufferers of this pandemic and it may lead them to face severe unavailability of essential resources and social support that, in turn, may result in distress, abuse and neglect and thus, may negatively impact their positive development and well-being (Avenue et al., 2020; Lee, 2020).

The physical and mental health problems for children aged 9-12 years and their parents have been well reported (Suffren et al., 2021). Studies in India reports that parents and families experienced a loss of social networks, employment, financial security and loss of life of their relatives that are negatively impacting their well-being and productivity in all life spheres (Parekh \& Dalwai, 2020; Saurabh \& Ranjan, 2020). Given the conditions of social disruptions, gender norm changes, school closure, lack of extracurricular/outdoor activities, new eating and sleeping habits, lack of peer relationships and boredom, their positive development may be seriously affected (Parekh \& Dalwai, 2020).

Among others, the restrictions of the pandemic have created undue and manifold demands on the parents and families to deal simultaneously with their stress, uncertainties, and loss on one hand and to save their children from it (Preuss et al., 2021). Now parents and families have to devote more time than 
before to supervise the daily activities, studies, play and well-being of their children and these increased role demands have increased their distress manifold (Kowal et al., 2020). The nature and types of families may differ in their abilities to face the challenges of the current pandemic due to differences in their processes and resources. For example, in absence of substitute care, parenting in countries like Austria and Germany has become even more challenging where the nuclear family system is more common (Petzold et al., 2020). Conversely, joint families may undergo dissimilar child-rearing experiences during the pandemic (Xiong et al., 2020).

A joint family refers to a consanguineal unit of two or more generations of kindred associated by either paternal or maternal line who use a common residence and are subject to common social, economic and religious regulations (Merriam-Webster Dictionary, 2020). Research suggests that the joint family system cultivates collective values that comprise interdependence, mutuality, shared identity, emotionality and concern for others (Cai et al., 2013; Gupta \& Sukamto, 2020). Research suggests that a joint family is more supportive of children to achieve psychological well-being than a nuclear family (Gul et al., 2017) due to dissimilarities in parent relations and social relations (Bernardi et al., 2013) and parental resources, parent-child relations, and quality of relationships (Fomby \& Cherlin, 2007). Children of joint families show better outcomes on well-being measures and performance indices (Gul et al., 2017) and lower scores on behavioural and emotional problems (Kondiba \& Hari, 2018). A joint family system may also help lower parental stress due to family structure and inner parenting model (Abidin, 1992; Brown et al., 2020).

\section{The current study}

Although there have been studies of the impacts of pandemics on children, they belong to the less severe than the current pandemic (Lee, 2020). Moreover, there has been limited research on the role of joint families in determining its impacts on children during the current pandemic (Jiao et al., 2020). A joint family is unique in its structure, nature of support and stimulations originating from the multiplicity of relationships among children, siblings, parents, grandparents and other relatives. The presence of grandparents may have unique effects on child-rearing in the pandemic period since they are more agreeable and emotionally stable (Steiner et al., 2012). Thus, strong bonds, positive environments, close monitoring, and promotion of family activities of joint families may have a distinct effect on parenting (Chadda \& Deb, 2013). Joint families also facilitate interdependence, obedience, proper behaviour, social obligations and group achievement (Junger-Tas et al., 2012).

The current study chose a qualitative research design to understand the protective roles of joint families to their children that carry relevance to capture individual, group and community responses as well as help to make sense of meaning, interactions, new insights, health and illness (Teti et al., 2020). We recruited full-time mothers to understand the life outcomes of their children as a significant source because they possess an in-depth understanding of the behaviours and experiences of their children in India (Tiwari et al., 2021). Mothers' perception may be helpful to develop an in-depth understanding of the behaviours of their children and develop an effective intervention plan. The study chose children aged 9- 
12 years since they remain dependent on their parents and other family members. These children can share their experiences with their parents, have some sense of social realities, life goals and broader human collectives (Tiwari et al., 2021). The study aimed to understand the roles of Indian joint families in protecting their children during the restrictions of the early phase of the COVID-19 lockdown.

\section{Materials And Methods}

\section{Research design, participants and recruitment}

Using a qualitative research design, the study recruited full-time mothers through convenience sampling. Twenty-nine mothers (age range $=35-45$ years, Mean $=39.28$ years, $S D=3.34$ ) gave their consent to participate initially in response to the study invitation sent by email, Facebook and WhatsApp, 25 mothers from Sagar, Madhya Pradesh, India finally responded to the interview questions who fulfilled the inclusion criteria of a full-time mother, affiliation with a joint family and at least one child aged between 9-12 years. They belonged mostly to middle-class Hindu families. The study was conducted during June and July 2020. The age of sample children ranged between 9 to 12 years (Mean $=10.52$ years, $S D=1.12)$. The study was approved by the Ethics Committee of the University [BLINDED FOR REVIEW], India. The demographics of the mothers and their children are displayed in Table 1.

\section{[TABLE 1 MAY BE PLACED HERE.]}

\section{Data Collection and analysis}

The participants were briefed about the basic goals of the study and the whole interviews were conducted through telephone calls. They were not paid any compensation for their participation. The data were collected by $2 \mathrm{nd}$, 3rd and 4 th authors on telephone calls using a semi-structured interview (mean duration $=51.12 \mathrm{~min}$.) protocol framed as per the goal of the study (The interview questions are given in Table 2). Saturation was reached at the 20th interview and 5 more data were collected to confirm it. The interviews contents were audio-taped, transcribed and analyzed through the thematic analysis method which comprises familiarisation, coding, theme generation, theme review, theme defining and naming, and writing (Braun \& Clarke, 2006). These authors read and reread transcripts and assigned codes to increase familiarity of the interview contents, inherent meaning and useful insights. Using a handwritten codebook, these codes were organized, merged and re-categorized to identifying relevant codes. An iterative approach was used to enhance insights which facilitated the generation of final codes with a set of relevant themes. Regular discussions, evaluations, consistent analysis, use of the codebook and evidence focus helped to achieve integrity.

\section{[TABLE 2 MAY BE PLACED HERE.]}

\section{Results}


Following the procedure of the thematic analysis method (Braun \& Clarke, 2006), six themes were generated which are described below with select relevant quotes:

\section{Theme 1: Perceived distress}

The novelty, uncertainties and strong fear caused the majority of the mothers to describe the situation as very distressful. These experiences are expressed in the following quotes:

We have never seen, read and thought about such painful times in our life. We were facing strong fear and depression. No medicine or vaccine was available. It was too fatal. (M_1)

We have never heard of this disease. It came abruptly and affected the whole human society. People were dying. Cry and the pain was everywhere. (F_3)

\section{Theme 2: Multiplicity of relationships}

Among others, the big distress of the family was to protect and engage their children. I could become easy with the unique strengths of the joint family where there is sufficient opportunities of play and entertainment, multiple learning resources, diverse instant and effective feedback system with a blend of reward and punishment, occurrences of positive behaviours (e. g., respect, morality, emotion regulation etc.), effective control, delay of gratification, good food habits (variety, frequency, amount etc.), awareness of worldly happenings, availability of alternatives to satisfy needs and diverse opportunities and sources of learning emotional, interpersonal and social skills. The mothers described these strengths of joint families happening during the pandemic in the following words:

We could face this odd situation since close relationships are there care for children. Members could engage the children in games, provide useful information, and create a positive and safe environment at home during the lockdown. (M_5)

We live in a joint family. The different age group of children could be engaged in themselves. Elder members watch them closely and made them involved in a variety of play (e.g., ludo, chess), helped in understanding the situation and realities of human life. (F_9)

\section{Theme 3: Harmonious relationships}

Despite small differences, joint families are generally headed by grandparents. They exercise full control over the behaviours of the members. Thus, we-feeling, shared identity, interdependence, compulsory cooperation, diverse outlet sources for negative emotions, manageable conflict, effective control mechanisms, availability of positive examples of couple relationships and practice of traditional roleexpectations of couple relationships due to the presence and practice of religiosity may have made the relationships harmonious in joint families. The following quotes reflected these realities:

Since we live in a joint family, we share food. The household works are divided as per experiences and skills. We have to care for one another. My grandfather-in-law closely monitors the whole family since 
they are always present. We become more united during the odds of life. (M_16)

We could manage the care of children since we all did it collectively. Generally, younger children remain playing and studying with their grandparents. My younger in-laws taught them regularly and punish them if they disobey. (F_6)

\section{Themes 4: Positive Engagement in Household activities}

Joint families work together cooperatively. They remain active and provide the opportunities for physical involvement, development of psychomotor skills, the development of social and emotional skills while doing homely tasks, effectively control life routine, the plenty of opportunities of creativity, reciprocity and values of labour. These strengths may have helped them to engage their children positively and saved them from boredom and distress which appeared in the majority of the mothers' descriptions. The following excerpts reflect some of these features:

With the school closure and restrictions on their play, their grandparents and uncles involved them in watering plants, care for pet cow and collect teacups. (M_11)

The children showed boredom initially. Their schedule was seriously disturbed. Gradually, the family elders assigned some household responsibilities such as helping grandparents to take medicine and milk at right time, arrange the clothes and care for pet animals. (F_7)

\section{Theme 5: Facilitating role of the elders}

The presence of the elderly was described as a big resource for the joint families during the pandemic. They satisfied various need during the bad time. It could become possible because they are affectionate, sensitive, optimistic, sociable, unselfish, supportive, humble, emotionally stable, compassionate, moral and express positive emotions more frequently. They also possess higher experiential knowledge of worldly life, positive life stories, effective emotion regulation strategies and generativity. They have positive life stories and generally acceptable to regulate the behaviours of family members and thus, buffer against the odds of life. The majority of the mothers described the presence of these attributes. Some of the similar reflections are:

My grandfather-in-law care and monitor the studies and play activities of the children. They generally tell stories full of joke, knowledge and morality. Family children regularly gather around them and ask them to tell the stories. They teach the children or motivate them to devote their time to studies. (M_14)

The lockdown restrictions were very fearful and uncertain. We regularly hear loss of someone's life. My grandfather-in-law consoles us and tells us that this time is very short. Everything will become normal. They take instances from Ramayan (A holy Hindu religious book). They regularly tell about their previous life challenges and their success stories to the children. They supervise their studies, play and whereabouts throughout the day. (F_2)

\section{Theme 6: Collective values and practices}


Joint families are the source of collective values. For example, interdependence, we-feeling (more use of 'we' instead of 'I'), shared identity, source of resistance to pain, compassion, tolerance, sacrifice, mutuality, closely-tied, group goal-orientation, bear ambiguities, relationship-orientation, and collective religious and spiritual practices are some of them. These values, actions and relationships may have helped to protect the children from facing distress and other worse negative outcomes.

Our family always become united in the face of external threats. We collectively face them. We do observe fast and do involve in Pooja (worship) regularly. It provides us with strengths during life adversities. (M_13)

The restriction was very painful and uncertain. We collective fought with it. We do care for one another. The family monitors the members including children to observe essential precautions. (F_5)

\section{Discussion}

The findings prove the contention that joint families come forward as a buffer mechanism against the fear, uncertainties and distress of the COVID-19 pandemic. This may have become possible because they carry many resources generally not available to people livening in nuclear families. The mothers described that the experience of the lockdown was distressing and painful due to its novelty, fatality and uncertainties (Theme 1). The finding lends support to previous research that reports similar experiences of the current pandemic for all age group people (Jiao et al., 2020; Tiwari et al., 2021; Wang et al., 2020).

The presence of relational resources in the form of a multiplicity of relationships was described (Theme 2). This is the basic feature of a joint family where a variety of relationships cohabitate. These relational resources have been suggested to be effective to deal with the negative outcomes during the pandemic (Fomby \& Cherlin, 2007; Tiwari et al., 2020). The mothers also described the presence of harmonious relationships in their families which help the children receive better care and protection from distress during the pandemic (Theme 3). Research reports that collective values of interdependence and shared identity function the joint families undisrupted (Sun \& Li, 2002). Theme 4 denotes that children were involved in some household activities which may have saved them from boredom and feel understimulated. These involvements provide a good opportunity to learn responsibilities, care, cooperation and we-feeling (Fomby \& Cherlin, 2007; Tiwari et al., 2020).

The presence of the elders in joint families was a dependable source during the hard times of the current pandemic (Theme 5). Research suggests that elder members are a good source of undisrupted affection, optimism, support and positive emotionality. Research also suggests that elders are more agreeable, report lesser neuroticism and higher positive emotionality than individuals of other age groups (Steiner et al., 2012). These strengths may have made them a good and effective buffer against the negativity and the fear of the current pandemic. They also provide moral support with their vast life experiences and successful skills of the previous life. Their positive roles in the current pandemic may have also guided by the presence of generativity that may have been useful in mentoring and raising children (Erikson \& Erikson, 1997). Their positive roles in dealing with the menace of the pandemic may have also added by 
their rich life experiences, wisdom, emotional maturity, positive stories and forgiveness (Ghaemmaghami et al., 2011). The presence of collective values and practices was also described by the mothers (Theme 6). Research suggests that joint families nurture and cultivate a set of collective values such as interdependence, shared identity, tolerance of ambiguities, compassion, group goal-orientation and collective enhancing- practices (Cai et al., 2013). These values may have acted as a collective mode of facing life threats caused by the current pandemic.

In conclusion, the study findings show that the mothers described the restrictions of the pandemic lockdown as distressful which affect badly the life outcomes of their children. The positive attributes of joint families such as the presence of a multiplicity of relationships with harmonious inclination, involvement in household activities, facilitating role of the elders and adherence to the collective values and practices extend essential protection, guidance, positive involvement and a way of life that may have buffered the children against the ill-consequences of the current pandemic.

The findings show that some form of family-based intervention may have helped the children to remain protected from the negative consequences of the pandemic. Group-based cognitive behaviour therapy, self-compassion therapy and mindfulness therapy may help guard families and children during hard times. Future research may attempt to understand the positive family process in diverse cultural groups relevant to face life adversities. The finding may be equally useful for researchers, practitioners, and policymakers to plan family-based intervention plans to face effectively the current and future pandemics.

\section{Declarations}

Competing Interests: the authors declare no competing interests.

\section{References}

1. Abidin, R. R. (1992). The Determinants of Parenting Behavior. Journal of Clinical Child Psychology, 21(4), 407-412. https://doi.org/10.1207/s15374424jccp2104_12

2. Avenue, H. R. W. | 350 F., York, 34th Floor | New, \& t 1.212.290.4700, N. 10118 - 3299 U. I. (2020, April 9). COVID-19's Devastating Impact on Children. Human Rights Watch. https://www.hrw.org/news/2020/04/09/covid-19s-devastating-impact-children

3. Bernardi, F., Härkönen, J., Boertien, D., Rydell, A., Bastaits, K., \& Mortelmans, D. (2013). Effects of family forms and dynamics on children's well-being and life chances: Literature review. Undefined. /paper/Effects-of-family-forms-and-dynamics-on-children\%27s-BernardiH\%C3\%A4rk\%C3\%B6nen/09aad957d844df88bc9672fff8f2e30ab1b9908c

4. Braun, V., \& Clarke, V. (2006). Using thematic analysis in psychology. Qualitative Research in Psychology, 3(2), 77-101. https://doi.org/10.1191/1478088706qp063oa 
5. Brown, S. M., Doom, J., Watamura, S., Lechuga-Pena, S., \& Koppels, T. (2020). Stress and Parenting during the Global COVID-19 Pandemic [Preprint]. PsyArXiv. https://doi.org/10.31234/osf.io/ucezm

6. Cai, H., Sedikides, C., \& Jiang, L. (2013). Familial Self as a Potent Source of Affirmation: Evidence From China. Social Psychological and Personality Science, 4(5), 529-537. https://doi.org/10.1177/1948550612469039

7. Chadda, R., \& Deb, K. (2013). Indian family systems, collectivistic society and psychotherapy. Indian Journal of Psychiatry, 55(6), 299. https://doi.org/10.4103/0019-5545.105555

8. Erikson, E. H., \& Erikson, J. M. (1997). The life cycle completed (Extended version). W.W. Norton.

9. Fomby, P., \& Cherlin, A. J. (2007). Family Instability and Child Well-Being. American Sociological Review, 72(2), 181-204. https://doi.org/10.1177/000312240707200203

10. Ghaemmaghami, P., Allemand, M., \& Martin, M. (2011). Forgiveness in Younger, Middle-Aged and Older Adults: Age and Gender Matters. Journal of Adult Development, 18(4), 192-203. https://doi.org/10.1007/s10804-011-9127-x

11. Gul, N., Ghani, N., Alvi, S. M., Kazmi, F., \& Shah, A. A. (2017). Family system's role in the psychological well-being of the children. Khyber Medical University Journal, 9(1), 29-32.

12. Gupta, M., \& Sukamto, K. (2020). Cultural Communicative Styles: The Case of India and Indonesia. International Journal of Society, Culture \& Language, 0, 1-16.

13. Jiao, W. Y., Wang, L. N., Liu, J., Fang, S. F., Jiao, F. Y., Pettoello-Mantovani, M., \& Somekh, E. (2020). Behavioral and Emotional Disorders in Children during the COVID-19 Epidemic. The Journal of Pediatrics, S002234762030336X. https://doi.org/10.1016/j.jpeds.2020.03.013

14. Junger-Tas, J., Marshall, I. H., Enzmann, D., Killias, M., Steketee, M., \& Gruszczynska, B. (2012). The Many Faces of Youth Crime: Contrasting Theoretical Perspectives on Juvenile Delinquency across Countries and Cultures. Springer New York. https://doi.org/10.1007/978-1-4419-9455-4

15. Kondiba, B. V., \& Hari, K. S. (2018). Emotional maturity among joint family and nuclear family children. The International Journal of Indian Psychology, 6(2), 109-112. https://doi.org/10.25215/0602.217

16. Kowal, M., Coll-Martín, T., Ikizer, G., Rasmussen, J., Eichel, K., Studzińska, A., Koszałkowska, K., Karwowski, M., Najmussaqib, A., Pankowski, D., Lieberoth, A., \& Ahmed, O. (2020). Who is the Most Stressed During the COVID-19 Pandemic? Data From 26 Countries and Areas. Applied Psychology: Health and Well-Being, 12(4), 946-966. https://doi.org/10.1111/aphw.12234

17. Lee, J. (2020). Mental health effects of school closures during COVID-19. The Lancet Child \& Adolescent Health, S2352464220301097. https://doi.org/10.1016/S2352-4642(20)30109-7

18. Merriam-Webster Dictionary. (2020). Definition of Joint family. https://www.merriamwebster.com/dictionary/joint+family

19. Parekh, B. J., \& Dalwai, S. H. (2020). Psychosocial Impact of COVID-19 Pandemic on Children in India. Indian Pediatrics, 57(12), 1107-1107. https://doi.org/10.1007/s13312-020-2060-y 
20. Petzold, M. B., Bendau, A., Plag, J., Pyrkosch, L., Mascarell Maricic, L., Betzler, F., Rogoll, J., Große, J., \& Ströhle, A. (2020). Risk, resilience, psychological distress, and anxiety at the beginning of the COVID-19 pandemic in Germany. Brain and Behavior, 10(9). https://doi.org/10.1002/brb3.1745

21. Preuss, H., Capito, K., van Eickels, R. L., Zemp, M., \& Kolar, D. R. (2021). Cognitive reappraisal and selfcompassion as emotion regulation strategies for parents during COVID-19: An online randomized controlled trial. Internet Interventions, 24, 100388. https://doi.org/10.1016/j.invent.2021.100388

22. Saurabh, K., \& Ranjan, S. (2020). Compliance and Psychological Impact of Quarantine in Children and Adolescents due to Covid-19 Pandemic. The Indian Journal of Pediatrics, 87(7), 532-536. https://doi.org/10.1007/s12098-020-03347-3

23. Steiner, M., Allemand, M., \& McCullough, M. E. (2012). Do agreeableness and neuroticism explain age differences in the tendency to forgive others? Personality \& Social Psychology Bulletin, 38(4), 441453. https://doi.org/10.1177/0146167211427923

24. Suffren, S., Dubois-Comtois, K., Lemelin, J.-P., St-Laurent, D., \& Milot, T. (2021). Relations between Child and Parent Fears and Changes in Family Functioning Related to COVID-19. International Journal of Environmental Research and Public Health, 18(4), 1786.

https://doi.org/10.3390/ijerph18041786

25. Sun, Y., \& Li, Y. (2002). Children's Well-Being during Parents' Marital Disruption Process: A Pooled Time-Series Analysis. Journal of Marriage and Family, 64(2), 472-488.

https://doi.org/10.1111/j.1741-3737.2002.00472.x

26. Teti, M., Schatz, E., \& Liebenberg, L. (2020). Methods in the Time of COVID-19: The Vital Role of Qualitative Inquiries. International Journal of Qualitative Methods, 19, 160940692092096. https://doi.org/10.1177/1609406920920962

27. Tiwari, G. K., Singh, A. K., Parihar, P., Pandey, R., Sharma, D. N., \& Rai, P. K. (2021). Understanding the perceived psychological distress and health outcomes of children during COVID-19 pandemic. The Educational and Developmental Psychologist, 1-12. https://doi.org/10.1080/20590776.2021.1899749

28. Tiwari, G. K., Tiwari, R. P., Pandey, R., Ray, B., Dwivedi, A., Sharma, D. N., Singh, P., \& Tiwari, A. K. (2020). The life outcomes of children during COVID-19: Exploring the protective roles of the joint and nuclear families in India [Preprint]. Authorea: Open Research Collaboration and Publishing. https://doi.org/10.22541/au.159769493.33057412

29. United Nations Organization. (2020). Policy Brief: The Impact of COVID-19 on children (pp. 1-17).

30. Wang, C., Pan, R., Wan, X., Tan, Y., Xu, L., Mclntyre, R. S., Choo, F. N., Tran, B., Ho, R., Sharma, V. K., \& Ho, C. (2020). A longitudinal study on the mental health of general population during the COVID-19 epidemic in China. Brain, Behavior, and Immunity, 87, 40-48. https://doi.org/10.1016/j.bbi.2020.04.028

31. World Health Organization. (2021). Healthy At Home-Healthy parenting. https://www.who.int/campaigns/connecting-the-world-to-combatcoronavirus/healthyathome/healthyathome-healthy-parenting 
32. Xiong, J., Lipsitz, O., Nasri, F., Lui, L. M. W., Gill, H., Phan, L., Chen-Li, D., lacobucci, M., Ho, R., Majeed, A., \& McIntyre, R. S. (2020). Impact of COVID-19 pandemic on mental health in the general population: A systematic review. Journal of Affective Disorders, 277, 55-64. https://doi.org/10.1016/j.jad.2020.08.001

\section{Tables}

Table 1

Demographics of the Full-Time Mothers of the Joint Families and Their Children 


\begin{tabular}{|c|c|c|c|c|c|c|c|}
\hline \multirow[t]{2}{*}{ S. No. } & \multicolumn{3}{|c|}{ Details of the Mothers } & \multicolumn{3}{|c|}{ Details of the children } & \multirow[t]{2}{*}{ Codes } \\
\hline & Age (in yrs.) & Education & Domicile & Age (in yrs.) & Gender & Class & \\
\hline 1. & 39 & Graduate & Rural & 9 & Male & V Std. & M_1 \\
\hline 2. & 38 & X Std. & Rural & 11 & Female & VII Std. & F_1 \\
\hline 3. & 35 & Graduate & Urban & 12 & Male & VI Std. & M_2 \\
\hline 4. & 39 & XI VIII Std. & Rural & 9 & Female & V Std. & F_2 \\
\hline 5. & 37 & Graduate & Urban & 11 & Male & VII Std. & M_3 \\
\hline 6. & 44 & Postgraduate & Urban & 11 & Female & VII Std. & F_3 \\
\hline 7. & 35 & Graduate & Rural & 9 & Male & V Std. & M_4 \\
\hline 8. & 36 & XI VIII Std. & Rural & 10 & Male & VI Std. & M_5 \\
\hline 9. & 41 & X Std. & Urban & 11 & Female & VI Std. & F_4 \\
\hline 10. & 45 & Postgraduate & Rural & 12 & Male & VII Std. & M_6 \\
\hline 11. & 38 & XI VIII Std. & Rural & 11 & Male & VI Std. & M_7 \\
\hline 12. & 44 & XI VIII Std. & Urban & 9 & Female & V Std. & F_5 \\
\hline 13. & 39 & Postgraduate & Rural & 9 & Male & V Std. & M_8 \\
\hline 14. & 35 & Graduate & Rural & 12 & Male & VII Std. & M_9 \\
\hline 15. & 39 & XI VIII Std. & Urban & 11 & Female & VII Std. & F_6 \\
\hline 16. & 41 & Graduate & Rural & 11 & Female & VI Std. & F_7 \\
\hline 17. & 35 & Postgraduate & Rural & 12 & Male & VII Std. & M_10 \\
\hline 18. & 40 & XI VIII Std. & Urban & 11 & Male & VI Std. & M_11 \\
\hline 19. & 44 & X Std. & Rural & 9 & Male & V Std. & M_12 \\
\hline 20. & 38 & Postgraduate & Rural & 10 & Female & VI Std. & F_8 \\
\hline 21. & 44 & Graduate & Urban & 9 & Male & V Std. & M_13 \\
\hline 22. & 40 & Graduate & Rural & 10 & Male & VI Std. & M_14 \\
\hline 23. & 36 & XI VIII Std. & Urban & 12 & Female & VII Std. & F_9 \\
\hline 24. & 44 & Graduate & Rural & 11 & Male & VII Std. & M_15 \\
\hline 25. & 36 & Postgraduate & Urban & 11 & Male & VI Std. & M_16 \\
\hline Mean & 39.28 & & & 10.52 & & & \\
\hline SD & 3.34 & & & 1.12 & & & \\
\hline
\end{tabular}


Table 2

Interview Questions Asked to the Full-Time Mothers

S. Questions

No.

1. Can you please tell in detail the extent to which COVID-19 has impacted the life of your child?

2. Please describe the role of elders in supporting the children of the family during the pandemic.

3. How the relationships in your family helped your child during the pandemic?

4. How does your family involve the child in household task and what are its consequences?

5. How does your family work together to provide care for your child during the pandemic? 